\title{
Glass sand potentiality of bar sediments from Tista and Dharla rivers, Bangladesh
}

\author{
Ismail Hossain $^{1}$, Syed Sumsuddin Ahmed ${ }^{1}$, Md. Najmul Islam ${ }^{1}$, Pradip Kumar \\ Biswas $^{2} \&$ Md. Aminur Rahman ${ }^{2}$ \\ ${ }^{1}$ Department of Geology and Mining, University of Rajshahi, Rajshahi 6205, \\ Bangladesh; ${ }^{2}$ Institute of Mining, Mineralogy and Metallurgy, Joypurhat, \\ Bangladesh. \\ *Corresponding author: ismail_gm@ru.ac.bd
}

\begin{abstract}
The present investigation deals with the glass sand potentiality of the bar sediments of Tista and Dharla rivers from different locations of Nilfamari, Lalmonirhat and Kurigram districts, Bangladesh. Accordingly, fourteen samples were selected for grain size distributions with separation of magnetic minerals. Magnetic mineral content ranges from about trace amount to $0.06 \mathrm{wt} \%$. Light minerals separated by tetrabromoethane technique ranging from about 88 to 98 wt\%. Moreover, glass sand as final products by flotation process evaluation ranges from 58 to $80 \mathrm{wt} \%$, which indicate good quantity of glass sand. Geochemical data also suggest that glass sands are suitable for commercial grade glass owing to its $\mathrm{SiO}_{2}$ content (80.7-94.1 wt\%). In particular, the Tista Barrage site shows high $\mathrm{SiO}_{2}\left(94.1\right.$ wt\%) with reasonably low $\mathrm{Al}_{2} \mathrm{O}_{3}, \mathrm{TiO}_{2}$, and $\mathrm{MgO}+\mathrm{CaO}$ percentages, which suggest an excellent glass grade quality. Unfortunately, some impurities (e.g., $\mathrm{Fe}_{2} \mathrm{O}_{3}, \mathrm{Zr}$ ) are comparatively higher than standards, which poses difficulties making high grade glass. However, if it is possible to remove and/or decrease the major impurities, it may be used to manufacture high grade glass (colourless glass).
\end{abstract}

Keywords: Glass sand, commercial grade glass, Tista and Dharla rivers, bar sediments, Bangladesh.

\section{Introduction}

Natural glasses form on Earth during rapid cooling of melts ranging in composition from basalt to rhyolite. Early humans used natural glasses such as obsidian for specific purposes, such as cutting tools or arrowheads. Glass is also one of the oldest artificial materials known to man. For more than 7000 years, glass has played an important role in the everyday life of humans and in the evolution of technological materials (Galoisy, 2006; Dararutana et al., 2007). Normally glass making sand contains high silica $\left(\mathrm{SiO}_{2}\right)$, which resembles of small grains or particles of mineral quartz and rock fragments. Other components may include aluminium, sodium, potassium and iron-bearing minerals. There are abundant deposits of silica sand or industrial sand in the eastern part of Bangladesh, e.g., Kulaura glass sand of Moulabibazar district, Teliapara and Shajibazar in the Hobigang district, Chauddagram and Noyapara Dattashah in Commilla district, Lalghat and Lakmachara in Sylhet district, and Balijuri Mouja in Jamalpur district (Islam, 1986; Imam, 1996). Whereas, there is no recognizable source of glass sand in the north-western part of Bangladesh and there is no 
extensive study for such purposes in this region, although northern parts of Bangladesh also hold huge potentialities of glass sand. Accordingly, field investigations have been undertaken at bar deposits of Tista and Dharla rivers to locate silica deposits from which high quality silica sand can be explored for glass making. The Tista and Dharla rivers flow over the northern part of the Bengal Basin, and are carried huge amount of sediments from the Himalayan catchment areas during rainy season (Figure 1). The investigated river bars are located within the proximal part of the Tista fan area (Reimann, 1993) as a part of the Rangpur Saddle, which is a significant tectonic feature of Bangladesh. As sedimentary bar silica sand is a common source for commercial silica, the sand must be free of mica, organic matter, iron, titanium, trace elements. The typical compositions of the most widely used industrial glasses have not changed much from antiquity to modern times, e.g., the process of glass making record from the ancient Iraq Royal Library of Assur-bani-pal al Nineveh in the seventh century BC (Dararutana et al., 2007). However, modern glass properties have been greatly improved not only by the contemporary technologies of fusion, fining and glass fabrication, but also by the addition of small amounts of trace elements that play explicit roles. For the present investigation of glass sand the US Bureau of Standard (US standard, 1965) and the British standard methods (British standard, 1988) were followed. This paper provides some positive messages about glass sand from bar sands of Tista and Dharla rivers and its quality for glass making.

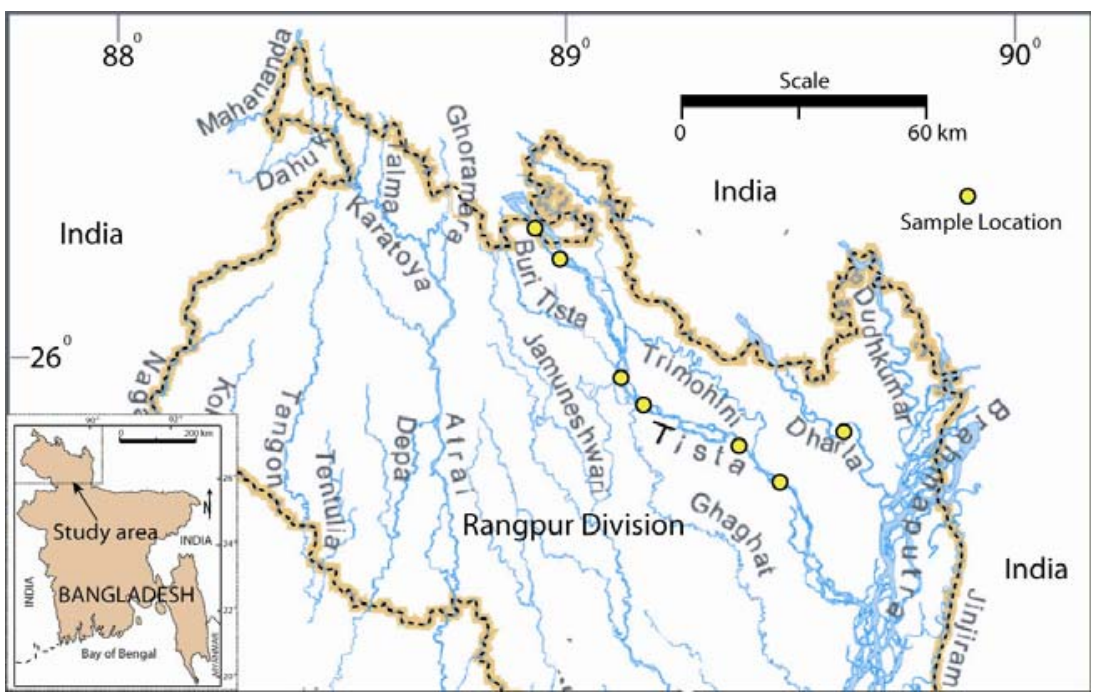

Figure 1. Location map of the study area.

\section{Materials and methods}

Sample collection and preparation

The collected samples from bars were selected mainly on the basis of variations in color, compositions, particle size, concentration of minerals and considerable 
distances. These samples were collected either from erosional or depositional banks with subsurface or surface of the bars. A hand auger used for collecting sample from subsurface of the bars. To know the partial mineralogical composition, a hand lens was used in the field. The collected samples were properly numbered and packed in the polyethylene and cotton bags for laboratory analysis. Primarily collected raw and wet samples were dried in sunlight.

Sizing

The samples were filtered and dried at $35{ }^{\circ} \mathrm{C}$ overnight. Each sample was sieved on a Ro Tap using US standard 30-, 100-, 140-, 200-, 270-, and 270-mesh. These size frictions were weighed and bagged after ten minutes of screening, and the weight distribution was properly calculated.

Magnetic separation

Size fractions from 30- to 140-mesh were used for magnetic separation due to their high weight percentages, while other fractions were avoided for their insignificant quantity. A powerful hand magnet was used for separation of magnetic minerals.

Heavy liquid separation

In the present investigation, heavy liquid mainly tetrabromoethane (1,1,2,2tetrabromoethene) was utilized to separate heavy minerals as sink product, while the glass sand as the float product. The term "heavy mineral" is commonly applied to those minerals which sink in heavy liquid (density 2.96). In other word, the minerals having specific gravity greater than 2.96 treated as heavy mineral. The heavy minerals separation was carried out by the standard tetrabromoethane technique (specific gravity 2.96), using separating funnel fitted to iron rod stand with the help of clip. Filter paper was used in open glass conical funnel and placed under the separating funnel with the help of iron ring attached with stand. Taking requisite quantity of tetrabromoethane in the funnel, $20 \mathrm{gm}$ of sample was poured in it (funnel). The heavy minerals were started to sink through the tetrabromoethane at the lower closed end of the clipped funnel. This position was kept about 2.5 hours with intermittently stirred. After settling the heavies, the grains were separated by opening the lower end of separating funnel for a short period with the help of clip. As soon as the heavy minerals were collected on the filter paper, the clip was closed. Then the tetrabromoethane was removed from separated floats and heavy minerals by washing with isopropyl alcohol. Floats were again washed with alcohol. Primarily all sinks and floats were dried in open air. Then the sinks and floats were left to dry in an oven overnight, weighted and preserved carefully.

Flotation process evaluation

The flotation process consisted of conditioning the material at $60-70 \%$ solids within a biker for approximately five minutes at a $\mathrm{pH}<3$ maintained with sulfuric acid. The conditioned pulp was adjusted to $25 \%$ solids and the iron mineral impurities were floated as the float product. The discharge was dewatered and again conditioned at approximately $40 \%$ solids for one minutes with an amine (methylamine) and a frothier at a maintained $\mathrm{pH}<3$. The conditioned pulp was adjusted to $25 \%$ solids and the mica floated as the float product. Then again 
discharge was dewatered and conditioned at around $40 \%$ solids for one minutes with an amine (methylamine), $\mathrm{HF}$, and a frothier at a maintained $\mathrm{pH}<3$. The conditioned pulp was adjusted to $25 \%$ solids and the feldspar impurities floated as the float product leaving the biker as the final glass sand product (Carpenter et al., 2000). All flotation products were filtered, dried, weighed, and again preserved carefully (Table 3).

Chemical analysis

The standard chemical analyses of selected six glass sand samples and their chemical compositions were determined by wavelength-dispersive X-ray Fluorescence spectrometer at the Institute of Mining, Mineralogy and Metallurgy (BCSIR) laboratory, Joypurhat. Primarily the selected samples were crushed for 20 minutes in a planetary ball mill (PM-200, Retsch, Germany) to make powder form in well mixing conditions. The powder samples were then pulverized in a pulverizer machine. The finely ground powder $(<100 \mu \mathrm{m})$ was then put in a porcelain crucible and dried at $100^{\circ} \mathrm{C}$ in an oven overnight to remove moisture. The dried powder samples were mixed with binder (stearic acid : sample at a ratio of 1:10) and pulverized for two minutes. The resulting mixture was spooned into an aluminum cap (30mm). The cap was sandwiched between two tungsten carbide pellets using a manual hydraulic press with 10-15 tons/sq. in. for 2 minutes and finally pressure was released slowly. The pellet was then ready for x-ray analysis and the elements were determined by the following the procedures of Goto \& Tatsumi $(1994,1996)$ using Rigaku ZSX Primus XRF machine equipped with an end window $4 \mathrm{KW}$ Rh-anode X-ray tube. The heavy and light elements were determined using $40 \mathrm{kV}$ voltage with $60 \mathrm{~mA}$ current and $30 \mathrm{kV}$ and $100 \mathrm{~mA}$ current respectively. Analytical uncertainties for XRF major and minor elements are 2\%.

\section{Results and discussion}

General analysis

From grain size analysis it is clear that the most of sand grains size fraction were within 30- to 140- mesh and its quantity about 81-99 wt\% (Table 1 and Table 2). The specifications of glass sand usually require the largest amount of material to be between 30- and 140- mesh (Carpenter et al., 2000). From grain size analysis, it shows that one individual mesh (mesh-100 or mesh-140) contains more than 80 wt\% portions of sand and it is more beneficial to increase production quality. The yield of sand after magnetic separation is about more than 99\%. To improve the magnetic separation process such as increasing hand magnet power and flotation processes would eliminate much of iron. The sand can be evaluated at two levels, one using a scrubbing technique along with magnetic separation, and other using flotation and magnetic separation. The scrubbing or flotation processes would eliminate much of iron. From heavy liquid separation floats products contain 88$98 \mathrm{wt} \%$ and rest of sink products (Table 2). Flotation results were reasonable and the yield of final glass sand was up to $80 \%$ by weight (Table 3 ). But due to traditional laboratory equipments, it is very much unfortunate that a few amount of marginal (gravity is more or less 2.96) minerals like biotite, muscovite, kyanite 
and some opaque still present in the glass sand, which might be increased the impurities of glass sand.

Table 1. Grain size analyses of bar sands of Tista and Dharla rivers.

\begin{tabular}{|c|c|c|c|c|c|c|c|c|}
\hline \multirow{2}{*}{$\begin{array}{c}\text { Sample } \\
\text { ID }\end{array}$} & \multicolumn{6}{|c|}{ Mesh Retained ( gm ) } & \multirow{2}{*}{$\begin{array}{l}\text { Total } \\
\text { (gm ) }\end{array}$} & \multirow{2}{*}{$\begin{array}{l}\text { Loss } \\
\text { (gm) }\end{array}$} \\
\hline & US 30 & $\begin{array}{c}\text { US } \\
100\end{array}$ & $\begin{array}{c}\text { US } \\
140\end{array}$ & $\begin{array}{c}\text { US } \\
200\end{array}$ & $\begin{array}{c}\text { US } \\
270\end{array}$ & $\begin{array}{c}\text { US } \\
>270\end{array}$ & & \\
\hline TRS-01 & 1.30 & 92.88 & 4.13 & 0.09 & 0.29 & 0.87 & 99.56 & 0.44 \\
\hline TRS-02 & 3.53 & 93.41 & 2.36 & 0.24 & 0.02 & 0.19 & 99.75 & 0.25 \\
\hline TRS-03 & 5.80 & 90.01 & 3.51 & 0.40 & 0.00 & 0.13 & 99.91 & 0.09 \\
\hline TRS-04 & 0.29 & 74.16 & 7.42 & 2.63 & 1.73 & 2.17 & 98.40 & 1.60 \\
\hline TRS-05 & 0.85 & 95.60 & 2.64 & 0.16 & 0.24 & 0.46 & 99.95 & 0.05 \\
\hline TRS-06 & 2.02 & 80.78 & 12.41 & 1.49 & 1.19 & 1.37 & 99.26 & 0.74 \\
\hline TRS-07 & 0.25 & 0.11 & 90.32 & 2.80 & 2.74 & 3.10 & 99.32 & 0.68 \\
\hline TRS-08 & 0.22 & 60.07 & 28.08 & 4.04 & 3.07 & 3.61 & 99.09 & 0.91 \\
\hline TRS-09 & 0.22 & 38.18 & 42.34 & 10.39 & 5.73 & 2.92 & 99.78 & 0.22 \\
\hline TRS-10 & 0.03 & 45.33 & 36.85 & 7.40 & 3.94 & 5.57 & 99.12 & 0.88 \\
\hline DRS-11 & 0.65 & 54.60 & 32.82 & 4.12 & 3.76 & 3.41 & 99.36 & 0.64 \\
\hline DRS-12 & 0.79 & 88.69 & 6.41 & 1.36 & 1.86 & 0.58 & 99.69 & 0.31 \\
\hline DRS-13 & 1.24 & 89.22 & 5.92 & 1.24 & 1.14 & 0.99 & 99.75 & 0.25 \\
\hline DRS-14 & 3.95 & 87.07 & 5.49 & 0.87 & 0.55 & 1.38 & 99.31 & 0.69 \\
\hline
\end{tabular}

Table 2. Concentrations of light and heavy minerals (in gm and wt\%) from heavy liquid separation.

\begin{tabular}{|c|c|c|c|c|c|c|}
\hline $\begin{array}{c}\text { Sample } \\
\text { ID }\end{array}$ & $\begin{array}{c}\text { Light mineral } \\
(\mathrm{gm})\end{array}$ & $\begin{array}{c}\text { Light mineral } \\
(\mathrm{wt} \%)\end{array}$ & $\begin{array}{c}\text { Heavy mineral } \\
(\mathrm{gm})\end{array}$ & $\begin{array}{c}\text { Heavy mineral } \\
(\mathrm{wt} \%)\end{array}$ & $\begin{array}{c}\text { Loss } \\
(\mathrm{gm})\end{array}$ & $\begin{array}{c}\text { Loss } \\
(\mathrm{wt} \%)\end{array}$ \\
\hline TRS-01 & 18.83 & 95.20 & 0.95 & 4.80 & 0.22 & 1.10 \\
\hline TRS-02 & 17.98 & 90.08 & 1.98 & 9.92 & 0.04 & 0.20 \\
\hline TRS-03 & 18.19 & 93.23 & 1.32 & 6.77 & 0.49 & 2.45 \\
\hline TRS-04 & 18.30 & 91.68 & 1.66 & 8.32 & 0.04 & 0.20 \\
\hline TRS-05 & 17.56 & 88.24 & 2.34 & 11.76 & 0.10 & 0.50 \\
\hline TRS-06 & 18.03 & 91.62 & 1.65 & 8.38 & 0.32 & 1.60 \\
\hline TRS-07 & 18.18 & 94.69 & 1.02 & 5.31 & 0.80 & 4.00 \\
\hline TRS-08 & 17.93 & 91.25 & 1.72 & 8.75 & 0.35 & 1.75 \\
\hline TRS-09 & 18.35 & 92.03 & 1.59 & 7.97 & 0.06 & 0.30 \\
\hline TRS-10 & 18.85 & 95.54 & 0.88 & 4.46 & 0.27 & 1.35 \\
\hline DRS-11 & 18.62 & 93.33 & 1.33 & 6.67 & 0.05 & 0.25 \\
\hline DRS-12 & 19.54 & 97.85 & 0.43 & 2.15 & 0.03 & 0.15 \\
\hline
\end{tabular}

Geochemical analysis

Results of chemical analyses (Table 4) reveal that quality of glass sand is reasonable but some high impurities make uncertainty to produce high grade glass. Major elements mainly $\mathrm{SiO}_{2}$ ranges from 80.7 to 94.1 wt\% which are very sound for commercial grade glass, even high grade glass is possible in the sample GTS- 
05 (94.1 wt\%). Although $\mathrm{Al}_{2} \mathrm{O}_{3}$ (1.83 to 9.56 wt\%), $\mathrm{Na}_{2} \mathrm{O}$ (0.13-1.80 wt\%), $\mathrm{K}_{2} \mathrm{O}$ (0.31-2.72 wt\%) contents in few samples are high, these are possible to remove or decrease reasonably in laboratory. Whereas major impurities, mainly $\mathrm{Fe}_{2} \mathrm{O}_{3}$ are about 2.06 to $3.19 \mathrm{wt} \%$, is very much alarming for high grade glass. In these cases, due to present some heavies like biotite, muscovite, kyanite and some opaque, which might be contributed to increase its amount in the analyzed samples. Some trace elements as like Zr may also be alarming for production of high grade glass. According to American Ceramic Society, US Bureau of Standards and their proposed detailed chemical specifications for silica sand for making different types of glasses (Sundararajan et al., 2009), only one sample (GTS-05) nearly fulfills those specifications for high grade glass, except its main impurity $\left(\mathrm{Fe}_{2} \mathrm{O}_{3}\right)$.

Table 3. Concentrations of glass sand (in gm) from flotation process evaluation.

\begin{tabular}{|c|c|c|c|}
\hline Sample ID & Light mineral (gm) & Glass Sand (gm) & Glass sand (wt\%) \\
\hline GTS-01 & 18.83 & 11.02 & 58.52 \\
\hline GTS-03 & 18.19 & 11.61 & 63.83 \\
\hline GTS-05 & 17.56 & 10.41 & 59.28 \\
\hline GTS-06 & 18.03 & 10.44 & 57.91 \\
\hline GTS-07 & 18.18 & 11.64 & 64.03 \\
\hline GTS-08 & 17.93 & 13.62 & 75.96 \\
\hline GTS-10 & 18.85 & 11.98 & 63.55 \\
\hline GDS-11 & 18.62 & 14.89 & 79.97 \\
\hline
\end{tabular}

Table 4. Geochemical analyses of the investigated glass sands of Tista and Dharla rivers.

\begin{tabular}{|c|c|c|c|c|c|c|c|c|}
\hline $\begin{array}{l}\text { Oxides } \\
\text { (wt } \%)\end{array}$ & GTS-01 & GTS-03 & GTS-05 & GTS-07 & GTS-08 & GDS-11 & $\begin{array}{c}\text { US Standard } \\
\text { (1965) }\end{array}$ & $\begin{array}{c}\text { British } \\
\text { Standard } \\
(1988)\end{array}$ \\
\hline $\mathrm{SiO}_{2}$ & 86.40 & 81.90 & 94.10 & 89.70 & 80.70 & 81.90 & 95 (min.) & 98.5 (min.) \\
\hline $\mathrm{Al}_{2} \mathrm{O}_{3}$ & 5.53 & 8.93 & 1.83 & 4.63 & 9.56 & 9.09 & 4 (max.) & - \\
\hline $\mathrm{Fe}_{2} \mathrm{O}_{3}$ & 3.19 & 2.93 & 2.24 & 2.06 & 2.48 & 2.34 & 1 (max.) & 0.30 (max.) \\
\hline $\mathrm{MnO}$ & 0.04 & 0.03 & 0.03 & 0.03 & 0.03 & 0.03 & & \\
\hline $\mathrm{TiO}_{2}$ & 0.12 & 0.15 & 0.06 & 0.12 & 0.15 & 0.18 & & \\
\hline $\mathrm{K}_{2} \mathrm{O}$ & 0.80 & 1.71 & 0.31 & 1.15 & 2.72 & 2.08 & & \\
\hline $\mathrm{Na}_{2} \mathrm{O}$ & 1.15 & 1.72 & 0.13 & 0.73 & 1.73 & 1.80 & & \\
\hline $\mathrm{MgO}$ & 1.12 & 0.95 & 0.28 & 0.12 & 0.45 & 0.86 & \multirow{2}{*}{\}$_{0.5(\max .)}$} & \multirow{2}{*}{0.5 (max.) } \\
\hline $\mathrm{CaO}$ & 0.65 & 0.67 & 0.12 & 0.42 & 0.94 & 0.95 & & \\
\hline $\mathrm{P}_{2} \mathrm{O}_{5}$ & 0.01 & 0.01 & 0.01 & 0.01 & 0.02 & 0.03 & & \\
\hline
\end{tabular}

In detailed investigations, experiments and chemical analyses of the selected float samples (glass sand) confirm that the most of samples show commercial grade glass quality according to industrial minerals guide book (Harben, 2005). In particular, the Tista Barrage site (sample GTS-5) shows reasonably high content of 
$\mathrm{SiO}_{2}$ (94.1 wt\%) with low content of $\mathrm{Al}_{2} \mathrm{O}_{3}$ (1.83 wt\%), $\mathrm{TiO}_{2}$ (0.06 wt\%), $\mathrm{MgO}+\mathrm{CaO}(0.40 \mathrm{wt} \%), \mathrm{Na}_{2} \mathrm{O}(0.13 \mathrm{wt} \%), \mathrm{K}_{2} \mathrm{O}(0.31 \mathrm{wt} \%)$ and $\mathrm{MnO}(0.03 \mathrm{wt} \%)$, which has an excellent glass grade quality, though its $\mathrm{Fe}_{2} \mathrm{O}_{3}$ (2.24 wt\%) is comparatively higher than the standards (US standard, 1965; British standard, 1988). On the other hand, most of the samples show considerably good $\mathrm{SiO}_{2}$ percentages (>81 wt \%; Table 4), which is well suited for glass making industries (BGS, 2009). From overall observations, these specific types of glass sand could be used for the ceramic grade, foundry grade silica, filtration sand, and possibly sodium silicate feedstock and silica flour. It is very remarkable that these glass sands at least fulfill medium to low grade glass (commercial colored glass) requirements. Unfortunately, some impurities (e.g., Fe and $\mathrm{Zr}$ ) in the samples make uncertainty to produce higher grade glass (colorless glass). Due to very traditional techniques for overall experiments, therefore the results are affected by some obvious limitations. Using modern techniques and development of laboratory facilities, it would be possible to eliminate/decrease these impurities reasonably to produce high grade glass.

\section{Acknowledgements}

We thank the Director, Institute of Mining, Mineralogy and Metallurgy (IMMM), Joypurhat, Bangladesh for his cordial support to carryout geochemical analysis. We are also acknowledged anonymous reviewers for their constructive review and positive comments. This study was partly supported by a project of the University of Rajshahi.

\section{References}

BGS (British Geological Survey) 2009. Mineral planning fact sheet, silica sand. British Geological Survey, Natural Environmental Research Council. Retrieved from: http://www.bgs.ac.uk/mineralsuk/planning/mineralPlanningFactsheets.html on 13 March 2014.

British Standard 1988. BS 2975 British standard methods for sampling and analyze of glassmaking sand. Retrieved from: http://shop. bsigroup.com/ProductDetail/?pid $=000000000030159622$ on 13 March 2014 .

Carpenter, L.A., Mensah-Biney, R. \& Miller, J.W. 2000. Glass-sand potential of the pinehurst formation in Richmond county, North Carolina: processing and mineral characterization. Environmental Studies, Report 16. University of North Carolina at Asheville.

Dararutana, P., Chetanachan, P., Wathanakul, P. \& Sirikulrat, N. 2007. Investigations on local quartz sand for application in glass industry. In: Satake K. (ed): Advances in Geosciences, Solid Earth. World Scientific Publishing Company, 13:23-29.

Galoisy, L. 2006. Structure-property relationships in industrial and natural glasses. Elements, 2:293-297.

Goto, A. \& Tatsumi, Y. 1994. Quantitative analysis of rock samples by an X-ray fluorescence spectrometer (I). The Rigaku Journal, 11(1):40-59.

Goto, A. \& Tatsumi, Y. 1996. Quantitative analysis of rock samples by an X-ray fluorescence spectrometer (II). The Rigaku Journal, 13(2):20-38. 
Harben, P.W. 2005. The industrial minerals handbook: a guide to markets, specifications \& prices. $4^{\text {th }}$ edition. Industrial Minerals Information Services, UK.

Imam, B. 1996. Mineral Resources of Bangladesh. Bangla Academy, Dhaka. 1-159.

Islam, M.N. 1986. Glass sand deposits of Chauddagram area, Comilla district, Bangladesh. Records of the Geological Survey of Bangladesh, 4(5): 1-41.

Reimann, K.U. 1993. Geology of Bangladesh. Gebrüder Borntraeger, Berlin: 1-160.

Sundararajan, M., Ramaswamy, S. \& Raghavan, P. 2009. Evaluation for the beneficiability of white silica sands from the overburden of lignite mine situated in Rajpardi district of Gujarat, India. Journal of Minerals \& Materials Characterization \& Engineering, 8(9):701-713.

US Standard 1965. Glass production guide: production of the US Glass Association. 